\title{
MODIFIED FONTAN OPERATION IN FUNCTIONALLY UNIVENTRICULAR HEARTS: PREOPERATIVE RISK FACTORS AND INTERMEDIATE RESULTS
}

Renate Kaulitz, MD

Gerhard Ziemer, MD

Ingrid Luhmer, MD

Hans-Carlo Kallfelz, MD
Background: The modified Fontan operation has been proposed as definitive palliation for an increasing variety of hearts with complex univentricular anatomy. To eliminate the influence of different surgical strategies, only patients undergoing total cavopulmonary anastomosis were included in this retrospective study. Methods: Seventy-two patients had been operated on at ages ranging from 7 to 219 months, with 29 patients younger than 4 years. Twenty-three patients had mean pulmonary artery pressures higher than $15 \mathrm{~mm} \mathrm{Hg}$, elevated pulmonary arteriolar resistances $\left(>3 \mathrm{U} \cdot \mathrm{m}^{2}\right)$, or elevated end-diastolic ventricular pressure (>12 mm $\mathrm{Hg}$ ). Associated systemic or pulmonary venous anomalies were present in 22 patients (30\%), and atrioventricular valve incompetence was present in 21 patients (29\%). Results: The overall mortality rate was $9.7 \%(7 / 72)$. Variables with significant effects on postoperative mortality were associated systemic or pulmonary venous anomalies, atrioventricular valve incompetence, mean pulmonary artery pressure greater than $15 \mathrm{~mm} \mathrm{Hg}$, and prolonged cardiopulmonary bypass time. Postoperative morbidity resulted mainly from atrial arrhythmia (20\%). Clinical signs of protein-losing enteropathy or atrial thrombi were rare $(3 \%$ and $6 \%$, respectively). Postoperative hemodynamic data from 48 surviving patients $(74 \%)$ revealed a mean transpulmonary gradient of $6.3 \mathrm{~mm} \mathrm{Hg}$, systemic venous pressure greater than $12 \mathrm{~mm} \mathrm{Hg}$ in only 10 patients, and cardiac index less than 3 $\mathrm{L} \cdot \mathrm{min}^{-1} \cdot \mathrm{m}^{-2}$ in 18 patients. Conclusion: In a high proportion of hearts with complex univentricular anatomy, associated anomalies, and borderline hemodynamics, the Fontan operation can be performed as a total cavopulmonary anastomosis with acceptable intermediate postoperative morbidity and hemodynamic results. (J Thorac Cardiovasc Surg 1996;112: 658-64)
$F_{\mathrm{p}}^{\mathrm{o}}$ r many years, operations based on the Fontan principle, with separation of the systemic and pulmonary venous return, have been regarded as the definitive palliation for hearts with various forms of functionally univentricular anatomy. Although more complex forms are now being functionally repaired by modified Fontan procedure, the results have

From the Division of Pediatric Cardiology, Children's Hospital and Division of Thoracic and Cardiovascular Surgery, Surgical Center, Hannover Medical School, Hannover, Germany.

Received for publication Dec. 1, 1995; revisions requested Jan. 26, 1996; revisions received Feb. 23, 1996; accepted for publication Feb. 26, 1996.

Address for reprints: Renate Kaulitz, MD, Division of Pediatric Cardiology, Children's Hospital, K.-Gutschow Str. 8, 30623 Hannover, Germany.

Copyright (C) 1996 by Mosby-Year Book, Inc.

$0022-5223 / 96 \$ 5.00+0 \quad \mathbf{1 2 / 1 / 7 3 0 9 8}$ improved significantly, with an overall mortality rate lower than $10 \% .^{1,2}$ With increasing experience, many of the preoperative selection criteria defined by Choussat and colleagues ${ }^{3}$ in 1978 may therefore be exceeded, mainly with respect to associated systemic and pulmonary venous anomalies, atrioventricular valve abnormalities, pulmonary vascular hemodynamics, surgically accessible distortion of the pulmonary arteries, or age at operation. ${ }^{4-6}$

Most follow-up studies have included a large number of patients who underwent systemic venouspulmonary artery connection, performed by a variety of techniques including atrioventricular connections and atrioarterial connections (by direct anastomosis or conduit implantation in the pulmonary artery). 4, 7, 8 Since 1986 , the Fontan procedure with total cavopulmonary anastomosis, which excludes most of the original right atrial wall from the 
Table I. Preoperative risk evaluation

\begin{tabular}{lrr}
\hline & No. & \multicolumn{1}{c}{$\%$} \\
\hline Age at operation <4 yr & $29 / 72$ & 40.2 \\
Systemic or pulmonary venous anomalies & $22 / 72$ & 30.5 \\
Atrioventricular valve malformation & $42 / 72$ & 58.3 \\
Pulmonary artery distortion & $7 / 72$ & 9.7 \\
Mean pulmonary artery pressure $>15 \mathrm{~mm} \mathrm{Hg}$ & $10 / 68$ & 14.7 \\
Pulmonary arteriolar resistance $>3 \mathrm{U} \cdot \mathrm{m}^{2}$ & $9 / 68$ & 13.2 \\
Systemic ventricular filling pressure $>12 \mathrm{~mm} \mathrm{Hg}$ & $4 / 68$ & 5.8 \\
\hline
\end{tabular}

Fontan circulation, has been performed in an increasing number of cases. ${ }^{9-11}$ Compared with the atriopulmonary connection, this modification was supposed to have the following advantages: reproducibility irrespective of atrial and atrioventricular valve morphology, reduction of the risk of early and late arrhythmias (because less right atrial wall remains at high pressure), low risk of surgical damage of the sinus node artery, and favorable flow patterns within the systemic venous pathway, with reduced risk of atrial thrombosis. ${ }^{10,11}$

We report here the early and intermediate results in 72 patients after modified Fontan operation, analyzed with respect to preoperative risk factors and operative variables and their potential influence on intermediate outcome and hemodynamic parameters. To allow a more unbiased evaluation, only patients with total cavopulmonary anastomoses were included in this retrospective study.

\section{Patients and methods}

Patients. Since 1988, 72 of 90 patients undergoing Fontan operations for various forms of functionally univentricular hearts underwent total cavopulmonary anastomoses and were included in this retrospective study. Informed consent was obtained from all patients or their parents. Age at operation varied from 7 to 219 months (median 54 months). Tricuspid atresia was the primary cardiac malformation in five patients. Eighteen patients had a double-inlet of left (16) or right (two) ventricle, with or without straddling atrioventricular valves. Forty-nine patients $(68 \%)$ had other complex forms of univentricular hearts, including left atrioventricular valve stenosis or atresia, common atrioventricular valve, left or right ventricular hypoplasia, and double-outlet ventricle.

Fourteen patients (19\%) had such favorable preoperative hemodynamic situations that they had not required any palliative procedures. Most patients had undergone previous shunt procedures. A bipulmonary Glenn anastomosis had been performed after previous shunt operation in 11 patients. Other palliative procedures included those to restrict pulmonary blood flow (pulmonary artery banding in six patients and Damus-Kay-Stansel procedure in
Table II. Preoperative hemodynamic data $(n=68)$

\begin{tabular}{lcc}
\hline & Mean $\pm S D$ & Range \\
\hline Mean PA pressure $(\mathrm{mm} \mathrm{Hg})$ & $11.9 \pm 3.4$ & $5-27$ \\
$\mathrm{R}_{\mathrm{p}}\left(\mathrm{U} \cdot \mathrm{m}^{2}\right)$ & $1.9 \pm 0.7$ & $1-4.2$ \\
$\mathrm{SV}_{\mathrm{ed}}(\mathrm{mm} \mathrm{Hg})$ & $6.3 \pm 2.6$ & $2-15$ \\
$\mathrm{Qp}\left(\mathrm{L} \cdot \mathrm{min}^{-1} \cdot \mathrm{m}^{-2}\right)$ & $3.7 \pm 1.5$ & $1.6-9.4$ \\
$\mathrm{Qp} / \mathrm{Qs} \mathrm{ratio}$ & $1.0 \pm 0.5$ & $0.4-2.9$ \\
Arterial oxygen saturation $(\%)$ & $80.4 \pm 6.2$ & $66-97$
\end{tabular}

$S D$, Standard deviation; $P A$, pulmonary artery; $R_{p}$, pulmonary arteriolar resistance; $S V_{e d}$, systemic ventricular end-diastolic pressure.

one patient) and resection of subaortic stenosis (two patients).

The decision to proceed with the modified Fontan operation was made on an elective basis in 16 cases of patients who were in good clinical condition and were principally candidates for a Fontan operation. Fifty-six patients needed further operation because of increasingly severe cyanosis or-rarely-congestive heart failure.

Preoperative risk evaluation was based mainly on patients' age, associated anomalies, atrioventricular valve morphology and function, and hemodynamic parameters. Derived from recent publications, ${ }^{4,5,12}$ these potential risk factors are summarized for our patient group in Table I. Preoperative hemodynamic variables were derived from cardiac catheterization data (Table II); calculation of pulmonary blood flow and resistance could not be performed in four cases.

Operative variables for modified Fontan operation included additional procedures (resection of subaortic stenosis, procedures for pulmonary artery or atrioventricular valve reconstruction, correction of partial or total anomalous pulmonary venous drainage, additional anastomosis of left persistent superior vena cava to left pulmonary artery), cardiopulmonary bypass time, early postoperative systemic venous atrial pressure, and early and late mortality.

Variables for the intermediate postoperative follow-up included need for reoperation, incidence of late arrhythmias, protein-losing enteropathy and atrial thrombi. Late rhythm disturbances-sinoatrial node dysfunction, supraventricular tachycardia, or atrial flutter-were documented by 12-lead surface electrocardiography or Holter electrocardiography. The New York Heart Association functional class was determined, with some limitations because of the young age of some patients. Postoperative hemodynamic parameters derived from postoperative cardiac catheterization were available for $48(74 \%)$ of the surviving patients at a mean of $28.5 \pm 18$ months after operation.

Statistical analysis. All data were analyzed with SPSS statistical software system (SPSS Inc., Chicago, Ill.). When appropriate, data were expressed as the mean value ( \pm standard deviation). Numeric data were analyzed with the unpaired Student's $t$ test; categoric variables were analyzed with $\chi^{2}$ analysis. Variables potentially predictive of postoperative death were tested in a stepwise logistic regression model. A $p$ value lower than 0.05 was considered significant. 


\section{Results}

With respect to preoperative risk evaluation, as noted in Table I, 29 patients ( $40 \%$ ) were younger than 4 years. Associated systemic (bilateral superior vena cava and azygos continuation in seven and six patients, respectively) or pulmonary venous anomalies (total and partial anomalous pulmonary venous drainage in six and three patients, respectively) were found in 22 patients $(30 \%)$. Heterotaxia syndrome (asplenia or polysplenia) was identified in seven patients. Atrioventricular valve morphology turned out to be normal in only 30 patients (42\%); atrioventricular valve incompetence, as semiquantitatively graded by colorflow mapping, was demonstrated in $29 \%$. Analysis of preoperative hemodynamic data revealed elevated mean pulmonary artery pressure $(>15 \mathrm{~mm} \mathrm{Hg})$ and elevated pulmonary arteriolar resistance $\left(>3 \mathrm{U} \cdot \mathrm{m}^{2}\right)$ in 10 and nine patients, respectively. The mean ratio of pulmonary blood flow (Qp) to systemic blood flow (Qs) was $1.0 \pm 0.5 ; 39$ patients had a $\mathrm{Qp} / \mathrm{Qs}$ ratio lower than 1.0. At least one preoperative morphologic or hemodynamic risk factor was present in 55 of 72 patients $(76 \%)$.

Surgical results. Associated with the risk potential of early age at operation, nine patients had fenestration of the intraatrial tunnel. Procedures in addition to total cavopulmonary anastomosis were performed in 25 cases (35\%), mainly for reconstruction of the pulmonary artery system or additional left superior vena cava-left pulmonary artery anastomosis (nine patients) or resection of subaortic stenosis (five patients). Two patients underwent atrioventricular valve reconstruction or patch closure of the right-sided atrioventricular valve. The early postoperative mean systemic venous pressure did not correlate with either the preoperative mean pulmonary artery pressure or the pulmonary arteriolar resistance.

The overall mortality rate was $9.7 \%$ (7/72 patients); five of these patients died during the early postoperative period. All of the patients who died had at least one of the preoperative risk factors determined by regression analysis. Preoperative and postoperative variables were entered into a stepwise logistic regression analysis to assess the combined effects of preoperative morphologic, hemodynamic, and surgical characteristics (Table III). Age at operation, pulmonary arteriolar resistance, and early postoperative systemic venous pressure had no significant effects on overall mortality. Variables with significant effects on postoperative mortality were associated systemic venous and pulmonary venous anomalies, atrioventricular valve incompetence, mean pulmonary artery pressure greater than $15 \mathrm{~mm} \mathrm{Hg}$, and prolonged cardiopulmonary bypass time. Compared with patients without associated venous anomalies, patients with anomalous systemic venous or pulmonary venous connections $(n=17)$ were characterized by older age at operation (94 \pm 66 vs $60 \pm 48$ months, $p=0.024$ ), prolonged cardiopulmonary bypass time ( $221 \pm 143$ vs $136 \pm$ 36 minutes, $p=0.028$ ), and higher early postoperative systemic venous pressure $(16 \pm 2.8$ vs $14 \pm$ $2.8 \mathrm{~mm} \mathrm{Hg}, p=0.019$ ). Analysis of the perioperative data in five of the 17 nonsurvivors (29\%) revealed a significant difference from survivors with respect to cardiopulmonary bypass time (382 \pm 187 vs $162 \pm 47$ minutes, $p=0.04)$ and early postoperative systemic venous pressure $(19 \pm 2.4$ vs $15 \pm 2.3 \mathrm{~mm} \mathrm{Hg}, p=0.015)$. When assessing preoperative morphologic and hemodynamic variables, associated pulmonary venous anomalies (as described in 9/72 patients) turned out to have the highest impact on cardiopulmonary bypass time. Surgical results improved significantly with more recent date (calendar year) of operation.

Postoperative morbidity. Sixty-five survivors could be followed up for a mean duration of 48 months (range 12 to 89 months; Table IV). Postoperative arrhythmias, including sinoatrial node dysfunction (seven patients) and supraventricular tachycardia or atrial flutter (six patients), were documented by 24hour Holter electrocardiography in $20 \%$. There was a trend toward higher prevalence of arrhythmias with increased length of follow-up ( $p=0.048$ ) but not in correlation with postoperative parameters such as right atrial pressure and cardiac index. Nine patients underwent pacemaker insertion because of sinoatrial node dysfunction or postoperative complete atrioventricular block.

Ten patients underwent reoperation during the first 3 months after operation (including one Fontan takedown); four patients needed pericardiotomy for chronic pericardial effusion and two patients underwent reoperation for residual atrial shunting or anastomosis-stenosis. One late reoperation each was performed for resection of subaortic stenosis and atrioventricular valve reconstruction. None of the patients had clinical or echocardiographic signs of pulmonary venous obstruction.

Two patients had clinical and laboratory signs of protein-losing enteropathy 9 and 38 months after 
Table III. Surgical outcome: comparison of surviving and nonsurviving patients

\begin{tabular}{|c|c|c|c|c|}
\hline & Total $(n=72)$ & Survivors $(n=65)$ & Nonsurvivors $(n=7)$ & $p$ \\
\hline Mean age at operation (mo) & $68 \pm 54$ & $67 \pm 52$ & $81 \pm 77$ & 0.430 \\
\hline \multicolumn{5}{|l|}{ Diagnosis } \\
\hline TA & 5 & 5 & - & \multirow[t]{3}{*}{0.535} \\
\hline DIV & 18 & 17 & 1 & \\
\hline Complex SV & 49 & 43 & 6 & \\
\hline \multicolumn{5}{|l|}{ Morphologically SV } \\
\hline Left & 40 & 37 & 3 & \multirow[t]{2}{*}{0.476} \\
\hline Right & 32 & 28 & 4 & \\
\hline \multicolumn{5}{|l|}{ Systemic vein return } \\
\hline Normal & 59 & 56 & 3 & \multirow[t]{2}{*}{0.004} \\
\hline Abnormal & 13 & 9 & 4 & \\
\hline \multicolumn{5}{|l|}{ Pulmonary vein return } \\
\hline Normal & 63 & 59 & 4 & \multirow[t]{2}{*}{0.010} \\
\hline Abnormal & 9 & 6 & 3 & \\
\hline \multicolumn{5}{|l|}{ Atrioventricular valve morphology } \\
\hline Normal & 30 & 28 & 2 & \multirow[t]{2}{*}{0.198} \\
\hline Abnormal & 42 & 37 & 5 & \\
\hline \multicolumn{5}{|l|}{ Atrioventricular valve incompetence } \\
\hline Absent & 43 & 41 & 2 & \multirow[t]{2}{*}{0.002} \\
\hline Present & 21 & 18 & 3 & \\
\hline Mean PA pressure $(\mathrm{mm} \mathrm{Hg})$ & $11.9 \pm 3.4$ & $11.6 \pm 3.4$ & $14.6 \pm 3.8$ & 0.055 \\
\hline$>15 \mathrm{~mm} \mathrm{Hg}$ & 10 & 7 & 3 & 0.024 \\
\hline $\mathbf{R}_{\mathrm{p}}\left(\mathbf{U} \cdot \mathrm{m}^{2}\right)$ & $1.9 \pm 0.77$ & $1.9 \pm 0.79$ & $2.1 \pm 0.76$ & 0.442 \\
\hline$>3 \mathrm{U} \cdot \mathrm{m}^{2}$ & 9 & 8 & 1 & 0.918 \\
\hline $\mathrm{Qp}\left(\mathbf{L} \cdot \mathrm{min}^{-1} \cdot \mathrm{m}^{-2}\right)$ & $3.7 \pm 1.5$ & $3.7 \pm 1.5$ & $3.7 \pm 0.67$ & 0.985 \\
\hline Qp/Qs ratio & $1.0 \pm 0.52$ & $1.0 \pm 0.54$ & $1.1 \pm 0.39$ & 0.550 \\
\hline Arterial oxygen saturation $(\%)$ & $80 \pm 6.1$ & $81 \pm 6.1$ & $78 \pm 6.9$ & 0.361 \\
\hline Cardiopulmonary bypass time ( $\min$ ) & $157 \pm 84$ & $139 \pm 34$ & $319 \pm 189$ & 0.045 \\
\hline Systemic venous atrial pressure $(\mathrm{mm} \mathrm{Hg}$ ) & $15 \pm 2.4$ & $15 \pm 2.3$ & $17 \pm 1.7$ & 0.286 \\
\hline
\end{tabular}

$T A$, Tricuspid atresia; $D I V$, double-inlet ventricle; $S V$, systemic ventricle $S D$, Standard deviation, $P A$, pulmonary artery; $R_{p}$, pulmonary arteriolar resistance.

operation. In addition, one of these patients turned out to have asymptomatic late partial intraatrial thrombosis, as diagnosed by routine postoperative echocardiography. Late postoperative cardiac catheterization in this patient demonstrated poor ventricular function as a result of right coronary artery occlusion; both patients had elevated right atrial pressures of 14 and $16 \mathrm{~mm} \mathrm{Hg}$.

Partial atrial thrombosis occurred early and late after operation in three patients and one patient, respectively. Two patients had clinical symptoms of elevated systemic venous pressure or atrial tachyarrhythmia; both patients underwent surgical thrombectomy. The other two patients received thrombolytic therapy, resulting in complete resolution of atrial thrombi.

The general functional status could be described by the New York Heart Association classification in 57 cases; it was sometimes impossible to perform a quantitative exercise test, especially for the large group of young patients. About $65 \%$ of the patients for whom functional class could be assessed were in
Table IV. Intermediate results $(n=65)$

\begin{tabular}{lcr}
\hline & No. & $\%$ \\
\hline Arrhythmia & & \\
None & 43 & 66 \\
SND & 7 & 11 \\
SVT & 6 & 9 \\
Pacemaker & 9 & 14 \\
Reoperation & 10 & 16 \\
PLE & 2 & 3 \\
Intraatrial thrombi & 4 & 6 \\
NYHA classification & & \\
I & $16 / 57$ & 28 \\
II & $22 / 57$ & 38
\end{tabular}

$S N D$, Sinoatrial node dysfunction; $S V T$, supraventricular tachycardia; $P L E$, protein-losing enteropathy; NYHA, New York Heart Association.

class I or II. A reliable comparison with preoperative status was not possible.

Forty-eight of the surviving patients $(74 \%)$ underwent postoperative cardiac catheterization, performed 2 to 75 months after operation (mean 28 months; Table V). With a mean systemic venous atrial pressure of $10.6 \mathrm{~mm} \mathrm{Hg}$, none of the patients 
Table V. Postoperative hemodynamic data

\begin{tabular}{lcccc}
\hline & & \multicolumn{2}{c}{ Residual right-to-left shunt } \\
\cline { 3 - 4 } & Total $(n=48)$ & Without $(n=38)$ & With $(n=10)$ & $p$ \\
\hline Postoperative interval $(\mathrm{mo})$ & $28.5 \pm 18.7$ & $30.2 \pm 18.9$ & $16.5 \pm 13.3$ & 0.09 \\
Mean systemic venous atrial pressure $(\mathrm{mm} \mathrm{Hg})$ & $10.6 \pm 2.9$ & $10.9 \pm 2.9$ & $9.0 \pm 1.0$ & 0.129 \\
Mean pulmonary artery pressure $(\mathrm{mm} \mathrm{Hg})$ & $10.3 \pm 3.1$ & $10.5 \pm 2.7$ & $9.3 \pm 1.0$ & 0.314 \\
Systemic ventricular end-diastolic pressure $(\mathrm{mm} \mathrm{Hg})$ & $4.7 \pm 2.0$ & $4.8 \pm 2.0$ & $4.2 \pm 1.7$ & 0.493 \\
Cardiac index $\left(\mathrm{L} \cdot \min ^{-1} \cdot \mathrm{m}^{-2}\right)$ & $3.2 \pm 0.8$ & $3.1 \pm 0.8$ & $3.4 \pm 0.5$ & 0.486 \\
Arterial oxygen saturation $(\%)$ & $93 \pm 4.3$ & $94 \pm 2.9$ & $86 \pm 5.8$ & 0.01 \\
\hline
\end{tabular}

turned out to have a significant gradient at the superior vena cava-pulmonary artery anastomosis; the mean transpulmonary gradient was $6.3 \mathrm{~mm} \mathrm{Hg}$. Mean systemic venous saturation and calculated cardiac output revealed normal cardiac indexes $(>3$ $\left.\mathrm{L} \cdot \min ^{-1} \cdot \mathrm{m}^{-2}\right)$ in 29 patients $(60 \%)$. Ten patients had systemic venous pressures greater than $12 \mathrm{~mm}$ $\mathrm{Hg}$, and 18 had cardiac indexes lower than $\mathrm{L} \cdot \min ^{-1} \cdot \mathrm{m}^{-2}$. There were no significant differences in postoperative systemic venous pressures with respect to underlying diagnosis, associated anomalies, and preoperative hemodynamic parameters. There was a trend toward lower postoperative cardiac output among patients with elevated venous pressure. Residual right-to-left shunting $(11 \%$ to $23 \%$ ) was related to atrial baffle fenestration (six patients) or to some leakage within the suture lines (four patients), leading to a trend toward higher postoperative cardiac output and lower systemic venous atrial pressure associated with significantly lower arterial oxygen saturation. One patient with significant residual shunting and arterial desaturation of $76 \%$ underwent reoperation during the early postoperative period.

\section{Discussion}

Preoperative risk evaluation and surgical results. Surgical modifications and increasing experience, especially in the field of postoperative management, allowed a more liberal definition of preoperative anatomic and hemodynamic selection criteria. ${ }^{4,6,13}$ In several publications, hemodynamic criteria that indicate increased risk for a Fontan procedure include elevated mean pulmonary artery pressure, pulmonary arteriolar resistance, and systemic ventricular end-diastolic pressure., 2, 12, 14,15 Because mean pulmonary artery pressure and pulmonary arteriolar resistance are highly associated with each other and calculation of preoperative pulmonary arteriolar resistance is dependent on pulmonary blood flow, resistance might be estimated as a second-degree influencing factor. In addition, there is a large variation (from 2 to $4 \mathrm{U} \cdot \mathrm{m}^{2}$ ) in the upper limit of pulmonary arteriolar resistance considered indicative of higher risk in various studies.* With respect to preoperative hemodynamic parameters, only mean pulmonary artery pressure turned out in our study group to be of significant effect if taken as a categoric variable $(>15 \mathrm{~mm} \mathrm{Hg})$; increased pulmonary arteriolar resistance $\left(>3 \mathrm{U} \cdot \mathrm{m}^{2}\right)$ and $\mathrm{Qp} / \mathrm{Qs}$ ratio below 1 were not associated with unfavorable outcome. The number of patients considered in this study is relatively small, however, and it might be possible for additional factors to be assessed as significant in a study with a larger number of patients.

Although Mayer and colleagues ${ }^{4}$ reported no significant effects of anomalies of systemic or pulmonary venous connection on outcome, we accepted these anatomic criteria as preoperative risk factors. Additional systemic venous to pulmonary artery anastomosis (such as in the presence of left persistent superior vena cava) or complex intraatrial baffle techniques necessary to separate pulmonary from systemic venous return in patients with heterotaxia syndrome might lengthen cardiopulmonary bypass time and involve the risk of obstruction of one or both venous pathways. In addition, total anomalous pulmonary venous drainage might also influence preoperative pulmonary vascular hemodynamics. We found a relatively high prevalence of associated pulmonary venous anomalies (in $13 \%$ of our patients). Our analysis of potential adverse effects of preoperative variables revealed an especially significant negative effect on mortality of associated systemic and pulmonary venous anomalies. The longer duration of cardiopulmonary bypass in these patients with correction of concomitant anomalies may have compromised postoperative

\footnotetext{
${ }^{*}$ References 4, 5, 12, 14, 16, and 17 .
} 
systolic and diastolic systemic ventricular function, with consequent increase in postoperative systemic venous pressure. The significantly elevated systemic venous atrial pressure in our nonsurviving patients immediately after operation may be indicative of such an effect.

Although abnormal atrioventricular valve morphology-mainly common atrioventricular valve and left atrioventricular valve hypoplasia-was not a determinant of postoperative mortality in our study, atrioventricular valve incompetence with the need for valve reconstruction had a significant negative effect on surgical outcome. Three of five nonsurviving patients for whom preoperative echocardiograms were available had moderate to severe atrioventricular valve incompetence, which is known to be one of the determinants of postoperative right atrial pressure.

There was no correlation in our study group between age at operation and early or late postoperative mortality. A potential risk of early Fontan procedure as a result of increased pulmonary vascular reactivity was not demonstrable, although 9 patients were younger than 12 months at operation. This may have been an effect of fenestrated total cavopulmonary anastomosis as performed in seven of these patients, which allows maintenance of cardiac output especially during the early postoperative period, when transient myocardial dysfunction or decreased diastolic ventricular function, arrhythmias, or respiratory insufficiency may be more easily overcome. ${ }^{12,18,19}$ Because the risk of earlier operation has decreased, most surgeons now recommend the Fontan procedure for 2- to 4-year-old patients, ${ }^{4,5,13,20}$ avoiding additional palliative procedures and preserving ventricular function.

Intermediate outcome and postoperative hemodynamics. With an incidence of $9 \%$ to $44 \%$, early and late postoperative arrhythmias are the most important determinants of postoperative morbidity and hospitalization. ${ }^{21-25}$ Associated with significant mortality, atrial flutter and junctional ectopic tachycardia turned out to be the most common arrhythmias during the early postoperative period. ${ }^{22,26}$ In contrast to these studies, none of our patients died because of early postoperative tachyarrhythmias. The overall incidence of late arrhythmias was low, without any significant relation to age at operation, underlying cardiac anatomy, or preoperative and postoperative hemodynamics; however, as described in other studies, ${ }^{23}$ early postoperative arrhythmias seemed to predict late arrhythmias. Although late arrhythmias occurred less frequently among patients after total cavopulmonary anastomosis than among those with atriopulmonary connections, ${ }^{25}$ patients are still at risk for further decline of sinus node function and development of late tachyarrhythmias.

The rate of early and late reoperations in our study group decreased with more recent date of operation and did not depend on age at operation or underlying cardiac malformation. Because reoperation for relief of subaortic stenosis could pose problems and still carries a significant mortality risk and because increased ventricular mass leads to impairment of ventricular compliance, ${ }^{27}$ we support myectomy and enlargement of the bulboventricular foramen before or simultaneously with the Fontan procedure.

The protein-losing enteropathy caused by intestinal lymphangiectasia resulting from increased systemic venous pressure usually occurred at least 6 months after the Fontan operation, even in the presence of favorable hemodynamics. ${ }^{28}$ In our two patients with protein-losing enteropathy, this condition was probably related to long-term elevated systemic venous pressure.

Atrial thrombi are assumed to occur early and late after operation, with a prevalence of $4 \%$ to $10 \%$, and in relation to venous stasis and increased systemic venous atrial pressure and size, with potential promotion by coagulation factor abnormalities. ${ }^{29-31}$ The relatively low prevalence also reported for our patients may be related to difficulties in diagnosing venous thrombosis by transthoracic echocardiography alone in patients without symptoms; transesophageal echocardiography turned out to have greater sensitivity and is considered mandatory. ${ }^{32}$ For optimal prophylactic anticoagulation treatment, most centers recommend warfarin for at least 3 months after operation, followed by aspirin. ${ }^{33,34}$ In all patients with low cardiac output, residual right-to-left shunts, and atrial arrhythmias, however, long-term anticoagulation with warfarin is indicated. $^{22,33}$

Even in patients without clinical symptoms, postoperative systemic venous pressure may be elevated to greater than $12 \mathrm{~mm} \mathrm{Hg}$ at rest. Because systemic venous pressure turned out to be independent of preoperative risk factors, hemodynamic outcome and long-term sequelae of the Fontan circulation are somewhat unpredictable. This unpredictability emphasizes the need for routine postoperative follow-up, including hemodynamic and electrophysiologic aspects as well as detailed laboratory investigations, to discover potential sequelae of the Fontan 
operation even in patients clinically free of symptoms. Such a course will allow optimization of long-term medical treatment and consequently of long-term surgical outcome.

\section{REFERENCES}

1. Fontan F, Kirklin KW, Fernandez G, Costa F, Naftel DC, Tritto F, et al. Outcome after a "perfect" Fontan operation. Circulation 1990;81:1520-36.

2. Mayer JE, Bridges ND, Lock JE, Hanley FL, Jonas RA, Castaneda AR. Factors associated with marked reduction in mortality for Fontan operations in patients with single ventricle. J Thorac Cardiovasc Surg 1992;103:444-52.

3. Choussat P, Fontan F, Besso P, Vallot F, Chauve A, Bricaud $\mathrm{H}$. Selection criteria for Fontan's procedure. In: Anderson R, Shineborne E, editors. Paediatric cardiology. New York: Churchill-Livinstone, 1977:559-60.

4. Mayer JE Jr, Helgason $\mathrm{H}$, Jonas RA, Lang P, Vargas FJ, Cook $\mathrm{N}$, et al. Extending the limits for modified Fontan procedures. J Thorac Cardiovasc Surg 1986;92:1021-8.

5. Bartmus DA, Driscoll DJ, Offord KP, Humes RA, Mair DD, Schaff HV, et al. The modified Fontan operation for children less than 4 years old. J Am Coll Cardiol 1990;15:429-35.

6. Weber HS, Gleason MM, Myer JL, Waldhausen JA, Cyran SE, Baylen BG. The Fontan operation in infants less than 2 years of age. J Am Coll Cardiol 1992;19:828-33.

7. Mair DD, Puga FJ, Danielson GK. Late functional status of survivors of the Fontan procedure performed during the 1970s. Circulation 1992;86(5 Suppl):II106-9.

8. Vargas F, Mayer JE, Jonas RA, Castaneda AR. Anomalous systemic and pulmonary venous connections in conjunction with atriopulmonary anastomosis (Fontan-Kreutzer): technical considerations. J Thorac Cardiovasc Surg 1987;93:523-32.

9. Puga FJ, Chiavarelli M, Hagler DJ. Modifications of the Fontan operation applicable to patients with left atrioventricular valve atresia or single atrioventricular valve. Circulation 1987;76(3 Pt 2):III53-60.

10. Jonas RA, Castaneda R. Modified Fontan procedure: atrial baffle and systemic venous to pulmonary artery anastomotic techniques. J Cardiac Surg 1988;3:91-6.

11. De Leval MR, Kliner P, Gewillig M, Bull C. Total cavopulmonary connection: a logical alternative to atriopulmonary connection for complex Fontan operations. J Thorac Cardiovasc Surg 1988;96:682-95.

12. Bridges ND, Mayer JE, Lock JE, Jonas RA, Hanley FL, Kean JF, et al. Effect of baffle fenestration on outcome of the modified Fontan operation. Circulation 1992;86:1762-9.

13. Myer JL, Waldhausen JA, Weber HS. A reconsideration of risk factors for the Fontan operation. Ann Surg 1990;211: 738-44.

14. Driscoll DJ, Offord K, Feldt R, Schaff H, Puga FJ, Danielson GK. Five- to fifteen-year follow-up after Fontan operation. Circulation 1992;85:469-96.

15. Kopf GS, Kleinman CS, Hijazi ZM, Fahey J'T, Dewar ML, Hellenbrand WE. Fenestrated Fontan operation with delayed closure of atrial septal defect. J Thorac Cardiovasc Surg 1992;103:1039-48.

16. Mair DD, Hagler DJ, Puga FJ, Schaff HV, Danielson GK. Fontan operation in 176 patients with tricuspid atresia: results and a new index for patient selection. Circulation 1990;82(5 Suppl):IV164-9.
17. Knott-Craig CJ, Danielson GK, Schaff HV, Puga FJ, Weaver AL, Discoll DD. The modified Fontan operation. J Thorac Cardiovasc Surg 1995;109:1237-43.

18. Mavroudis C, Zales VR, Backer CL, Muster AJ, Latson LA, Fenestrated Fontan with delayed catheter closure: effects of volume loading and baffle fenestration on cardiac index and oxygen delivery. Circulation 1992;86(5 Suppl):Ir85-92.

19. Castaneda AR, Bridges ND. The Fontan operation with a fenestrated patch: rationale and results. Cardiol Young 1993; 3:202-6.

20. Pearl JM, Laks H, Drinkwater DC, Capouya ER, George BL, Williams RG. Modified Fontan procedure in patients less than 4 years of age. Circulation 1992;86(5 Suppl):II100-5.

21. Gewillig M, Wyse RK, de Leval MR, Deanfield JE. Early and late arrhythmias after the Fontan operation: predisposing factors and clinical consequences. Br Heart J 1992;67:72-9.

22. Peters NS, Somerville J. Arrhythmias after the Fontan procedure. Br Heart J 1992;68:199-204

23. Weber HS, Hellenbrand WE, Kleinman CS, Perlmutter RA, Rosenfeldt LE. Predictors of rhythm disturbances and subsequent morbidity after the Fontan operation. Am J Cardiol 1989;64:762-7.

24. Balaji S, Johnson TB, Sade RM, Case C, Gillette PC. Management of atrial flutter after the Fontan procedure. J Am Coll Cardiol 1994;23:1209-15.

25. Gelatt M, Hamilton RM, McCrindle BW, Gow RM, Williams WG, Trusler GA, Freedom RM. Risk factors for atrial tachyarrhythmias after the Fontan operation. J Am Coll Cardiol 1994;24:1735-41.

26. Gewillig M, Lundstrom U, Wyse D, Deanfield J. Determinants and outcome of early and late arrhythmias after Fontan operation. J Am Coll Cardiol 1989;13:170-2.

27. Razzouk AJ, Freedom RM, Cohen AJ, Williams WG, Trusler GA, Coles JG, et al. The recognition, identification or morphologic substrate and treatment of subaortic stenosis after a Fontan operation: an analysis of twelve patients. J Thorac Cardiovasc Surg 1992;104:938-44.

28. Rothman A, Snyder J. Protein-losing enteropathy following the Fontan operation: resolution with prednisone therapy. Am Heart J 1991;121:618-9.

29. Cromme-Dijkhuis AH, Hess J, Húhlen K, Henkens CM, Bink-Boelkens MT, Eygelaar AA, et al. Specific sequelae after Fontan operation at mid- and long-term follow-up: arrhythmia, liver dysfunction, and coagulation disorders. $\mathbf{J}$ Thorac Cardiovasc Surg 1993;106:1126-32.

30. Dobell AR, Trusler GA, Smallhorn JF, Williams WG. Atrial thrombi after the Fontan operation. Ann Thorac Surg 1986; 42:664-7.

31. Mahony L, Nikaidoh H, Fixler DE. Thrombolytic treatment with streptokinase for late intraatrial thrombosis after modified Fontan procedure. Am J Cardiol 1988;62:343-4.

32. Fyfe DA, Kline CH, Sade RM, Gillette PC. Transesophageal echocardiography detects thrombus formation not identified by transthoracic echocardiography after the Fontan operation. J Am Coll Cardiol 1991;18:1733-7.

33. Jahangiri M, Ross DB, Redington AN, Lincoln C, Shinebourne EA. Thromboembolism after the Fontan procedure and its modification. Ann Thorac Surg 1994;58:1409-14.

34. Wilson DG, Wisheart JD, Stuart AG. Systemic thromboembolism leading to myocardial infarction and stroke after fenestrated total cavopulmonary connection. $\mathrm{Br}$ Heart J 1995; $73: 483-5$ 